\title{
El acto de incoación y las esferas jurídicas de los sujetos intervinientes en el procedimiento administrativo
}

\section{The action of initiating a proceeding and legal areas of the participants who are involved in the administrative procedure}

\section{ORLANDO VIGNOLO CUEVA*}

Resumen: El análisis del inicio del procedimiento administrativo plantea una serie de interrogantes que no solo deben responder a las implicancias adjetivas que tiene esta etapa procedimental, sino a sus dos modos de plasmación $-\mathrm{O}$, en un sentido más extenso, a su impacto directo sobre diversos términos y actuaciones posteriores que pueden surgir alrededor de la tramitación de este cauce formal- . Los argumentos y las respectivas conclusiones deben tratar de ubicarse más allá de la figura como una mera fase, a fin de presentarla como un acto que abre la puerta a un entramado de relaciones jurídico-administrativas entre dos sujetos de naturaleza distinta y que se encuentran en medio de un camino de diligencias y actuaciones normativamente predeterminadas. Por lo dicho, resulta claro que este acto permite revisar — de manera meridianamente clara - los estatutos conformados alrededor de los intervinientes en un procedimiento, quienes empezarían a desarrollarse con una serie de particularidades con la necesidad de ser resaltadas.

El presente trabajo pretende reconocer algunos de los componentes estatutarios de la organización administrativa y de los administrados, sin perder de vista los necesarios aspectos propios de la incoación como un paso de apertura dentro de la macrofigura llamada procedimiento administrativo.

Palabras clave: Incoación - procedimiento administrativo - administración pública - administrado - interesado - estatuto

Abstract: Analysis of initiating a proceeding of the administrative procedure raises many questions which have to be answered not only regarding to secondary implications of this procedure stage, or its two ways of expression or in a broad sense; but , to its direct impact over several terms and later proceedings that could arise around the processing of this formal path. Arguments and its conclusions must reach a position beyond the legal concept as a mere stage in order to present it as an action that opens the door to a framework of legal-administrative relations between two different nature subjects in a path of diligences and predetermined regulatory proceedings. Therefore, it is obvious that this action allows to verify — in a crystal clear way — the statutes

* Es doctorando por la Universidad de Zaragoza de España, así como abogado por la Universidad de Piura de Perú. Se desempeña como abogado asociado del Estudio Echecopar de Perú y como profesor de la Pontifica Universidad Católica del Perú. Asimismo, es miembro de la Unión Iberoamericana Municipalista. 
formed around the participants in a procedure, developing special features which is necessary to be highlighted.

It is the intention of the author to recognize some of these administrative organization statutory components and the applicants without losing sight of necessary inherent aspects of initiating a proceeding as a first step within the macro concept called «administrative procedure».

Key words: Initiating a proceeding - administrative procedure - public administration - applicant - interested party - statute

CONTENIDO: I. FUNDAMENTOS SOBRE EL ENFOQUE DEL TRABAJO. - II. EL INICIO DEL PROCEDIMIENTO ADMINISTRATIVO CONECTADO CON SU TRAMITACIÓN. - III. LOS ESTATUTOS DE LOS ADMINISTRADOS Y LA ADMINISTRACIÓN PÚBLICA ANTE EL INICIO DEL PROCEDIMIENTO ADMINISTRATIVO.

\section{FUNDAMENTOS SOBRE EL ENFOQUE DEL TRABAJO} ¿Qué razones pueden justificar el estudio del inicio del procedimiento administrativo común regulado en un puñado de artículos de nuestra Ley de Procedimiento Administrativo General (LPAG)? Más allá de los didácticos apuntes que intentan mostrar las diferencias entre estas actuaciones jurídicas por los modos de incoación, o de poner relevancia en las cuestiones adjetivas típicas del cómputo de plazos, en la interrupción de los plazos de prescripción o en el punto de inicio para desarrollar el resto de fases o en las diligencias que conforman este cauce ordenado — todas reflejadas o generadas por esta única actuación -1 , considero $-\mathrm{y}$ aquí sin dejar de reconocer la importancia de los anteriores temas, los cuales se centran, finalmente, en el régimen de producción de los actos administrativos ${ }^{2}$, su ejecución y operaciones materiales correspondientes ${ }^{3}$ - que existe la posibilidad real de mostrar un par de enfoques diferentes, relativos a las posiciones jurídicas de los dos tipos de sujetos participantes en estos caminos instaurados por el ordenamiento jurídico

1 Sobre estas primeras cuestiones, de las cuales daremos cuenta en la segunda parte de este artículo, puede revisarse en nuestra doctrina los siguientes trabajos: MoRón URBINA, Juan Carlos. “Comentarios a la Ley de Procedimiento Administrativo General». Gaceta jurídica, 2011, pp. 373-392, Lima; y ABRUÑA PUYOL, Antonio y Víctor BACA ONETO. Notas al curso de Derecho administrativo, pro manuscrito, pp. 296-298.

2 Ciertas tesis de inicios de la década pasada empezaron a cuestionar esta manera estática de mirar y analizar el procedimiento administrativo que se sustentaba en la influencia dominante que ha tenido «la figura del acto administrativo definitivo [...] Así, el procedimiento es presentado como una sucesión de actos administrativos de trámite, presentados generalmente de forma deslavazada». Esto, junto con otros componentes tradicionalmente estudiados en esta parte general del Derecho administrativo, habría ocasionado un descuido doctrinal clamoroso acerca de «la calidad de la actividad administrativa en el ejercicio de las potestades [...] el procedimiento administrativo puede y debe ser una institución jurídica que, además de constituir una defensa para los interesados, ayude a que la Administración administre bien y, en consecuencia, a que aumente las posibilidades de obtención de decisiones acertadas en su servicio a los intereses generales» (PONCE SOLÉ, Julio. Deber de una buena administración y derecho al procedimiento debido. Valladolid: Lex Nova, 2001, pp. 31-35.

3 Bermejo Vera, José. Derecho administrativo básico. Navarra: Thomson-Cívitas, 2008, p. 276. 
— me refiero tanto a la organización administrativa como a los propios administrados-.

El propósito expuesto encuentra sostén dentro de un contexto innegable: por un lado, el equilibrio que salta a borbotones cuando se afronta el estudio de esta figura jurídica-administrativa — demostrado en diversos tramos de las actuales relaciones entre la administración pública instructora o encargada de decidir la tramitación de un procedimiento y los privados incluidos en este- $-\mathrm{y}$, por el otro, mediante la delgada y a veces imperceptible línea que une a los principios de legalidad y de eficacia como dos pilares esenciales del llamado deber de buena administración.

Sobre el primer punto, el destacado profesor venezolano Brewer-Carías ha señalado en varios trabajos que el progresivo proceso de codificación del procedimiento administrativo en distintos países latinoamericanos - fenómeno del cual no escapó el nuestro, que celebra una década de su nacimiento- ha llevado a:

[liquidar] el desbalance de los dos extremos de la relación de la relación de derecho administrativo [...] las leyes de procedimiento administrativo han contribuido a generar en todos los países un cambio de actitud y de forma y método de actuar de la Administración pública, procurando que dejara de ser la Administración preponte que solo concedía dádivas o favores al administrado [...] Con las nuevas leyes se sentaron las bases para que ello cambiara, de manera que el administrado que la Administración iba a enfrentar ya no fuera un sujeto indefenso, sino uno bien armado con muchos derechos frente a la Administración y con muchos mecanismos jurídicos para garantizarlos ${ }^{4}$.

Acerca de la segunda consideración, debe tomarse en cuenta que si uno revisa el articulado de la LPAG —en específico, aquellas reglas recogidas en el título II de esta norma legal que conformarían la columna vertebral de la regulación del procedimiento común- se puede observar dos finalidades esenciales legadas por el legislador a los operadores. Por un lado, la garantía de la juridicidad de las actuaciones administrativas racionalizadas 5 mediante la ordenación procedimental — surgida desde el despliegue real y forzoso del principio de legalidad—-,

4 BREWER-CARíAs, Allan. «Los principios generales del procedimiento administrativo en la Ley 1437 de 2011 contentiva del Código de Procedimiento Administrativo y de lo Contencioso Administrativo de Colombia. En Visión actual de los procedimientos administrativos. Caracas: Editorial Jurídica Venezolana, 2011, p. 16.

5 Para el profesor Sánchez Morón, la racionalización de la función administrativa promovida por el procedimiento administrativo permite "garantizar el acierto de la decisión, es decir, que se trate de la decisión procedente y correcta en términos jurídicos y, si se trata de una decisión discrecional, también la más apropiada al interés general, ya sea en términos políticos, técnicos o económicos [...] Ello no obstante [...] tiene efectos menos elogiables, ya que impone un itinerario que resulta con frecuencia demasiado rígido y formal, sobre todo cuando se regula con excesiva minuciosidad, lo que es frecuente». (SÁNCHEZ MORÓN, Miguel. Derecho administrativo. Parte general. Madrid: Tecnos, 2010, p. 480).

\section{EL ACTO DE \\ INCOACIÓNYLAS \\ ESFERAS JURÍDICAS \\ DE LOS SUJETOS \\ INTERVINIENTES EN \\ EL PROCEDIMIENTO \\ ADMINISTRATIVO}

\section{THE ACTION OF}

INITIATING A

PROCEEDING AND

LEGAL AREAS OF

THE PARTICIPANTS

WHO ARE

INVOLVED INTHE

ADMINISTRATIVE

PROCEDURE 
y, por el otro, la necesidad de que la forma no atosigue al fondo, sino, más bien, se muestre como su indispensable complemento. Es decir, que el procedimiento permita mostrar prácticas administrativas basadas en «eficacia, eficiencia y economía [...] conectadas a una legitimidad por rendimiento $»^{6}$, y destinadas a alcanzar decisiones correctas y oportunas de cara al interés público.

Asimismo, la idea de tratamiento ordenado de los hechos de la vida social que se mueven en la esencia de este instituto también puede abonar en la propuesta de estudiar el inicio del procedimiento administrativo conjuntamente con el contenido de las esferas jurídicas de los partícipes en este. Es justamente sobre los primeros que deben recaer - de manera simultánea - las tres perspectivas sobre las cuales se despliega el procedimiento administrativo: personas, tiempo y materias. Es decir, son indispensables los específicos estudios sobre los «sujetos del procedimiento, el objeto del procedimiento y el desarrollo del procedimiento, cada uno de ellos con sus correspondientes problemas que reclaman una regulación, constituyendo así los núcleos sobre los que se debe reflexionar a fin de establecer las consecuencias jurídicas apropiadas»?

Claro, si uno mira estas cuestiones en la doctrina nacional, encontrará que la mayoría de los trabajos sobre el procedimiento administrativo han centrado su atención en el objeto y en la tramitación del «conjunto de actos y diligencias» que reza el artículo 29 de la LPAG, con lo que se mira al acto de incoación como una fase más, sin que exista el detenimiento para revisar la conexión de este con el conjunto de capacidades, condiciones, garantías o ejercicios de poderes de los intervinientes, y se relega cada uno de los últimos a análisis individualizados, sin asumir que son partes de un solo rompecabezas, pues la activación de un procedimiento —ergo, de la relación jurídico-procedimental — genera inmediatamente un estatuto peculiar en cada participante, lo cual no es otra cosa que un haz de relaciones jurídicas compuestas por «derechos, potestades, deberes y cargas, cuyo fundamento inicial tiene que estar en la Ley [...] la idea de la relación jurídica puede dar lugar a obligaciones accesorias en el marco del procedimiento, que también afectan, como cargas, a los particulares interesados, sin necesidad de una previsión legal expresa ${ }^{8}$.

Pues bien, entender integralmente el estatus de la administración - como poder público encargado de impulsar el procedimiento y de velar por la aplicación del equilibrio en su trámite- o del administradociudadano — como persona que defiende una pretensión de interés

6 PONCE SOLÉ, Julio. Ob. cit., pp. 121-122.

7 Schmidt-Assmann, Ederhard. La teoría general del Derecho administrativo como sistema. Madrid: INAP-Marcial Pons, 2003, p. 372

8 lbíd., p. 375. 
particular con precisas facultades y garantías - podría darnos una visión más cercana de la figura. Esto no solo como una mera sucesión de actos concatenados mediante el hilo conductor de la actividad administrativa, sino como una cabal obligación de medios — de seguimiento9- que impacta en realidades jurídicas a veces enfrentadas, otras tantas relativamente emparejadas, pero, en todos los casos, sometidas $-\mathrm{O}$ camino a ser sometidas - a la obtención de una decisión final, la cual debe gozar de características de diversa índole — muchas de ellas son deudoras de rasgos o contenidos jurídicos, además de otras peculiares características-. Si se quiere, el planteamiento en bloque busca resaltar la noción del camino institucional del procedimiento, que previamente fue diseñado por el legislador y la propia organización administrativa para materializar la legalidad en un grueso porcentaje de actuaciones de esta última. A la par, no debe olvidar su otro primordial fin: la consecución —en iguales términos, y a favor de los respectivos destinatarios- de «un comportamiento racional, objetivo, eficaz, eficiente y económico en el ejercicio de las funciones públicas» ${ }^{10}$.

Ahora bien, conseguir los objetivos descritos sin violentar las esferas jurídicas de la organización administrativa $-y$, por ende, del interés público_ - o del administrado no es tarea nada sencilla. Peor aún, si en el inicio de un determinado procedimiento participa, como un administrado más, una administración pública del otro lado de la orilla o varias privadas, o si esta tiene una estructura compleja y que viene necesitado de distintas intervenciones administrativas no aparecidas desde un solo órgano instructor. En todas estas situaciones se dificulta sobremanera la consecución del sello finalista explicado. Por eso, y encima de cualquier diagramación, cabe entender que, tras nuestro objeto de estudio, siempre debe aparecer el concepto de «justicia procedimental» como elemento del cual procede todo el engranaje de principios y subproductos que lo componen y definen ${ }^{11}$.

Luego, la administración pública también deberá tener presente que la tramitación procedimental supone — casi siempre- enfrentamientos e incertidumbres entre interesados concretos, así como complejas fórmulas de entrega de datos a terceros, fomentos para estimular y lograr la participación ciudadana, la constante obligación de simplificar pasos para eliminar el burocratismo y la rutina de actuación ${ }^{12}$, etcétera. Todos estos son problemas comunes, de los cuales debe intentar salir bien librada únicamente mediante el ejercicio de las potestades administrativas habilitadas por el ordenamiento. Por tanto, nuestra figura no 
solo comporta la elaboración de las decisiones administrativas ${ }^{13}$, sino que se convierte en un medio para demostrar el papel de árbitro entre fuerzas sociales ${ }^{14}$, un rol que no puede ser rehuido por las organizaciones administrativas. Esta labor supone la composición de intereses sin dejar de tener en cuenta «no solo el interés público primario — definido por el Poder Legislativo y representado por la Administración-, sino también los restantes intereses secundarios, ya sean públicos o privados, presentes en el ámbito de intervención de que se trate. Nótese por tanto [...] que el interés público deja de identificarse con el interés propio de la Administración y pasa a conceptuarse, en cambio, como el resultado final de una integración entre los diversos intereses concurrentes, entre ellos, claro es, los intereses legítimos de los particulares afectados» ${ }^{15}$.

\section{II.EL INICIO DEL PROCEDIMIENTO ADMINISTRATIVO CONECTADO CON SU TRAMITACIÓN}

El inicio del procedimiento administrativo común ha sido previsto por los artículos 103, 104 y en ciertas reglas dispersas en los artículos siguientes de la LPAG como una actuación dúctil, que puede ser promovida — como regla general — tanto por una organización administrativa como a «instancia del administrado». Claro está que esta cuestión inicial tiene límites, pues existen supuestos donde la doble posibilidad quedaría eliminada, ya que el objeto del mismo así lo impone o porque existe una expresa disposición normativa que fija la incoación procedimental en manos de uno de los intervinientes. Frente a esta primera impresión, los profesores Abruña y Baca han sabido reconocer, en particular referencia al señalado artículo 103 de la LPAG, que esta regla de flexibilidad ligada - finalmente - al tipo de procedimiento que se busca activar «proviene de los artículos 67 y 68 de la antigua Ley de Procedimiento Administrativo español que en su tenor literal señalaban que el procedimiento podrá iniciarse de oficio o a instancia de persona interesada [...] se incoará de oficio por acuerdo de órgano competente, bien por propia iniciativa o como consecuencia de orden superior, moción razonada de los subordinados $o$ denuncia» ${ }^{16}$ (las cursivas son nuestras).

En el mismo orden de ideas, es claro que el régimen de esta fase procedimental aparece reconocido por nuestro Poder Legislativo como una de las denominadas «reglas básicas de tramitación» ${ }^{17}$, imposibles de ser desconocidas por parte de la legislación nacional sectorial,

13 SÁNCHEZ MORÓN, Miguel. Ob. cit., pp. 479-480.

14 MARTIN-RETORTILLO, Sebastián. El reto de una administración racionalizada. Madrid: Cívitas, 1983, pp. 12 y siguientes.

15 Cierco SeIRA, César. La participación de los interesados en el procedimiento administrativo.

Valladolid: Lex Nova-Publicaciones del Real Colegio de España en Bolonia, 2002, p. 77.

17 SÁNCHEZ MORÓN, Miguel. Ob. cit., p. 491. 
y las prácticas reglamentarias que creen cauces especiales. Al menos, no cabe la posibilidad de que, irracionalmente, se excluya o aminore la pauta general expuesta. Sin embargo —y a reglón seguido—, debe dejarse la puerta abierta para la reducción a una sola opción de incoación, siempre y cuando la organización administrativa justifique su implantación por diversos motivos - principalmente centrados en la naturaleza y objeto del específico procedimiento tratado- y, a continuación, publicite la configuración aprobada ante los privados. Esto último debe entenderse como una de las obligaciones administrativas incardinadas en el deber de «calificación de procedimientos», los cuales deben estar reglados objetivamente por los principios, normas o criterios adjetivos pertinentes de la norma legal estudiada, cosa que deberá aparecer plasmada en el llamado Texto Único de Procedimientos Administrativos ${ }^{18}$.

Dicho esto, debe entenderse que cada una de las formas de iniciación tiene sus propias peculiaridades, desde donde se las puede considerar - $\mathrm{a}$ modo explicativo y no matemáticamente riguroso- como una bipartición nacida de «los efectos favorables o adversos que puede provocar la actuación administrativa en los patrimonios jurídicos de los sujetos destinatarios de la resolución» ${ }^{19}$. Sin embargo, sea como sea, la incoación quedará siempre en el ámbito decisorio del órgano administrativo competente ${ }^{20}$. Asimismo, es necesario asumir que, tras la configuración de estas fórmulas y el propio presupuesto formal de la legitimación - por encima de la mera capacidad jurídica-, siempre existe un administrado en una «particular relación con el objeto del procedimiento que, finalmente, se expresará en un acto administrativo», como dirían Acuña y $\mathrm{Baca}^{21}$.

Por un lado, el inicio de oficio ha sido reconocido por el artículo 104 de la LPAG como la fórmula en la que el procedimiento queda instruido - por decisión administrativa reglada o discrecional — de que en ningún caso depende de la solicitud o petición presentada por administrado alguno ${ }^{22}$. Es decir, «es un órgano el que decide comenzar, sin que nadie se lo pida, la tramitación de un expediente» ${ }^{23}$, con lo que se impone su práctica por expreso acto del órgano con competencia para su emisión -llamado por el Poder Legislativo «autoridad superior»—. Este acto

18 Ver el artículo 30 de la LPAG. El profesor Morón Urbina señala que la implantación de esta obligación administrativa se debió a la necesidad de superar «el error de la Ley de Simplificación Administrativa de haber implantado algunas directrices y dejar librado al criterio de cada entidad optar entre uno y otro procedimiento al momento de formular sus TUPA. Por ello, las normas siguientes contienen algunas directrices que retiran a los funcionarios la facultad de autocalificar procedimientos y se opta por que la ley califique algunos procedimientos para su reproducción por las entidades" (MORÓN URBINA, Juan Carlos. Ob. cit., p. 226).

19 Cierco SeIRA, César. Ob. cit., p. 159.

20 BeRmejo Vera, José. Ob. cit., p. 285.

21 ABRUÑa PuYol Antonio y Víctor BACA Oneto. Ob. cit., p. 243.

22 SÁNCHEZ MORÓN, Miguel. Ob. cit., p. 491.

23 Bermejo Vera, José. Ob. cit., p. 285.

\section{EL ACTO DE \\ INCOACIÓNY LAS \\ ESFERAS JURÍDICAS \\ DE LOS SUJETOS \\ INTERVINIENTES EN \\ EL PROCEDIMIENTO \\ ADMINISTRATIVO}

THE ACTION OF

INITIATING A

PROCEEDING AND

LEGAL AREAS OF

THE PARTICIPANTS

WHO ARE

INVOLVED INTHE

ADMINISTRATIVE

PROCEDURE 
podría venir revestido de diversos nombres ${ }^{24}$ tales como «acuerdo» o una «aparente resolución», sin que la nomenclatura usada pueda generar mayores efectos prácticos o diferenciados sobre terceros.

Los numerales 104.1 y 104.2 de la LPAG imponen un par de deberes formales que deberán ser cumplidos por el órgano encargado de esta actuación. Estos pueden resumirse en lo siguiente: el acto de inicio deberá contener razones de justificación basadas «en el cumplimiento de un deber legal o el mérito de una denuncia $»^{25}$ - existe una densidad mínima de los motivos-, y, en segundo lugar, debe concretarse la notificación del mismo con unos determinados datos imprescindibles — el señalamiento de la naturaleza jurídica del procedimiento, el plazo máximo para culminar su tramitación, y los derechos y obligaciones del privado involucrado en su desarrollo-, luego de lo que la notificación debe ser dirigida no solo al interesado, sino a los «administrados [...] cuyos intereses o derechos protegidos puedan ser afectados por los actos a ejecutar». Este último presupuesto formal puede ser completamente exonerado en su cumplimiento cuando exista fiscalización administrativa a posteriori «sobre solicitudes [...] documentación, acogidos a la presunción de veracidad», o también aplazado para una fecha posterior al verdadero inicio, cuando sea necesario por la «naturaleza confidencial basada en el interés público» del procedimiento, y exista expresa autorización normativa ${ }^{26}$.

En el mismo sentido, debe tenerse presente el relativo papel protagónico que tiene la denuncia en la gestión de los procedimientos comenzados por la voluntad administrativa, al permitirle a un sujeto - privado o público - la comunicación «a la autoridad competente de aquellos hechos que conociera contrarios al ordenamiento, sin necesidad de sustentar la afectación inmediata de algún derecho o interés legítimo, ni que por esta actuación sea considerado sujeto del procedimiento» ${ }^{27}$. Si se quiere, esta actuación —reconocida en el artículo 105 de la LPAGes «un acto de voluntad de una persona que se limita a poner en conocimiento de la Administración pública unos hechos, que podrían dar lugar a la incoación de un procedimiento. Pero tal conducta no confiere al denunciante la condición de interesado, esto es, no le otorga

24 MORÓN URBINA, Juan Carlos. Ob. cit., p. 375.

25 Estas dos opciones permitirían la posibilidad de que un órgano administrativo distinto al instructor pueda interponer una denuncia en la que se indique la falta de ejecución de una disposición legal en las actuaciones realizadas por un tercero. Con esto, debe entenderse que en «ningún caso la denuncia vincula al órgano competente para iniciar el procedimiento [...] tampoco esta circunstancia transforma al procedimiento iniciado de oficio en otro iniciado a instancia de parte» (SÁNCHEZ MORÓN, Miguel. Ob. cit., p. 491). Dicho esto, queda claro que el supuesto explicado aparece recogido implícitamente en el numeral 104.1 de la LPAG, con lo que se acerca su contenido — casi completamente- a su antecedente (el numeral 69.1. de la Ley española 301/1992).

26 Ver el numeral 104.3 de la LPAG.

27 Sedín García, Miguel Ángel. «Derechos de los ciudadanos relativos a la documentación en los procedimientos administrativos". En Desafíos del derecho administrativo contemporáneo. Caracas: Editorial Jurídica Venezolana, 2009, pp. 374-379. 
un derecho específico a intervenir en el procedimiento iniciado ${ }^{28}$. En otras palabras, este tipo de administrado no goza del llamado «derecho al procedimiento», ya que de ninguna manera puede iniciar su tramitación mediante el despliegue de su iniciativa, pues esta facultad le queda reservada a la administración pública, la cual deberá ponderar los datos aportados y decidir la iniciación del respectivo expediente ${ }^{29}$. Sin embargo, a pesar de estos fundamentos, esta construcción general - de completa disociación entre la calidad de denunciante e interesadodeberá matizarse para ciertos casos — como sucedería con la condición de «denunciante interesado» creada por mandato de la Ley $29542^{30}$ -

Lo indicado presupone que la denuncia — sin dejar de ser un medio de colaboración desinteresada y de ofrecimiento de datos para la administración pública (según frase de la jurisprudencia española: «un acto de excitación $»^{31}$ ), que, a priori, no inviste al sujeto específico de la cualidad de interesado- puede, en ciertas ocasiones, - esencialmente, en la preparación de procedimientos sancionadores- asumir la categoría de una actuación que no «enerve y liquide cualquier rasgo de interés legítimo en la posición del denunciante [...] la denuncia, si bien no atribuye per se la condición de interesado, tampoco constituye, desde luego, un impedimento para a la adquisición de la misma» ${ }^{32}$. Por tanto, como bien señaló Rebollo Puig, nada imposibilita en abstracto que el denunciante de una infracción administrativa pueda ser titular de un interés legítimo ${ }^{33}$.

La segunda forma de iniciación de un procedimiento se concretiza mediante la presentación de un pedido o de una solicitud de parte de una persona interesada. Este documento obligaría a la organización administrativa a comenzar los trámites correspondientes dentro de los términos normativamente impuestos ${ }^{34}$. Ergo, la solicitud de inicio aparece planteada como el derecho genérico del interesado de indudables efectos propulsivos «que va permitirle situar la primera pieza de un íter procedimental que en lo sucesivo habrá de progresar bajo el impulso del órgano

28 Bermejo VerA, José. Ob. cit., p. 285. Además, en la doctrina peruana también se ha aceptado esta concepción sobre la denuncia, al considerarla simplemente como la manifestación de «alguna situación administrativa no ajustada a derecho, con el objeto de comunicar un conocimiento personal, a diferencia de la petición que es la expresión de pretensión con interés personal, legítimo, directo e inmediato en obtener un comportamiento y resultado concretado de la autoridad, condiciones que no son exigibles a los denunciantes e instigadores» (MoRÓN URBINA, Juan Carlos. Ob. cit., p. 378).

29 Cierco SeIRA, César. La participación de los interesados en el procedimiento administrativo. Valladolid: Publicaciones del Real Colegio de España, Bolonia, 2002, pp. 165-166.

30 Sobre este nuevo régimen y sus criticables alcances daba cuenta en mi trabajo «El Poder Legislativo y el nuevo régimen de protección al denunciante en el ámbito administrativo y de colaboración eficaz en el ámbito penal aprobado por la Ley 29542». Revista Electrónica Ita lus Esto, año 3, número 6, pp. 153-172. (www.itaiusesto.com).

$31 \mathrm{Al}$ respecto puede revisarse las sentencias del Tribunal Supremo español del 18 de noviembre de 1967, f.j. 7; la del 28 de noviembre de 1983, f.j. 5; y la del 23 de enero de 1986, f.j. 6.

32 Cierco SeIRA, César. Ob. cit., pp. 167-168.

33 Rebollo Puig, Manuel. «Interesados y denunciantes en el procedimiento sancionador». En El procedimiento administrativo en el Derecho comparado. Madrid: Cívitas, 1993, p. 227 y siguientes. De la misma manera se pronuncia Sánchez Morón en Derecho administrativo. Parte general (p. 491).

34 BermeJo VerA, José. Derecho administrativo básico, p. 285.

EL ACTO DE

INCOACIÓNYLAS

ESFERAS JURÍDICAS

DE LOS SUJETOS

INTERVINIENTES EN

EL PROCEDIMIENTO

ADMINISTRATIVO

THE ACTION OF

INITIATING A

PROCEEDING AND

LEGAL AREAS OF

THE PARTICIPANTS

WHO ARE

INVOLVED INTHE

ADMINISTRATIVE

PROCEDURE 
responsable de la tramitación $»^{35}$. Pero, a continuación, esta idea original debe ser rápidamente complementada, pues a nuestro Poder Legislativo no le ha bastado con regular el mero «poder de iniciación» ${ }^{36}$, más bien, el artículo 106 de la LPAG va más allá, y desarrolla legislativamente el derecho constitucional a la petición en ámbitos procedimentales ${ }^{37}$. Esta opción legislativa se presenta como un régimen especial compuesto por la citada norma y por los artículos sucesivos — que van del 107 al 112-, con lo que se entrega la concepción de una variante del instituto constitucional con una mediana sustantividad conceptual - tiene un contenido peculiar que incluye diversas facultades y situaciones activas puestas a disposición del titular- y un nombre particular — por petición administrativa-.

Tal como se desprende de lo explicado, a diferencia del molde normativo español, que separa legislativamente las peticiones graciables o de naturaleza estrictamente discrecional — tales como las «sugerencias, ruegos, informaciones, quejas o súplicas, que pueden dirigirse [...] no solo a los gobiernos y autoridades administrativas, sino también a otros poderes públicos» ${ }^{38}$ reguladas en su Ley Orgánica 4/2001, y las solicitudes de interesados que inician un procedimiento administrativo preceptuadas en su Ley 30/1992, por las que el interesado «pretende una actuación administrativa sobre la base de un derecho o interés legítimo que entiende tutelado por el ordenamiento ${ }^{39}$-, nuestro Poder Legislativo ha introducido toda la regulación de la petición en lo referido a ámbitos estrictamente procedimentales en un solo cuerpo normativo (la LPAG), mediante la instauración de una sola figura (petición administrativa) que despliega sus diversos efectos a través de subfórmulas de aplicación - de acuerdo al supuesto concreto se podrá utilizar la petición de gracia, las solicitudes de iniciación procedimental, la solicitud de acceso a datos informativos, las consultas, etcétera-. Aunque pueda discutirse este régimen unificado de la petición administrativa - considero que la oportunidad de mezclar la petición de gracia y las solicitudes individuales o colectivas de incoación de procedimientos no parecen las más adecuadas-, en este temática se echa de menos la falta de regulación legal sobre peticiones de gracia dirigidas a poderes públicos distintos a la administración pública, lo cual es un descuido que deja a estas actuaciones libradas a su suerte y al libre albedrío de las instituciones receptoras.

Algunos apuntes extras sobre la petición lo muestran como un derecho reconocido inicialmente por el inciso 20 del artículo 2 de la Constitución, el cual permitiría la posibilidad libre de que un privado - sea persona 
natural o jurídica - pueda activar ejercicios de diversas potestades administrativas en cualquier situación imaginable, incluso en contextos extremos de completa orfandad de mecanismos impugnativos ${ }^{40}$. Se trata, por lo tanto, de un derecho que permitiría movilizar la respuesta del aparato administrativo cuando se han cerrado todas las opciones, cuando no exista ninguna otra posibilidad jurídica para presentar argumentos y cuando se busca que estos sean valorados por una organización administrativa — derecho a ser oído ${ }^{41}$ —, pero teniendo en claro que esta última, en virtud de sus amplias competencias discrecionales, no queda conectada o forzada a un determinado contenido o densidad de respuesta - en los motivos- Más concretamente, se ha pronunciado Hurtado Yelo indicado que este derecho «autoriza para dirigirse a los Poderes Públicos que se determinen legalmente y en los asuntos de su competencia, en solicitud de actos y decisiones [...] existiendo por parte de los órganos receptores de la petición la obligación de acusar recibo de la solicitud, contestarla de manera fundamentada y notificar la respuesta» ${ }^{42}$ (las cursivas son nuestras). De la misma manera, Fernández Sarasola indica que la petición es un «mecanismo a través del cual los ciudadanos pueden solicitar que se active una competencia cuyo ejercicio no resulta impuesto por el ordenamiento jurídico» ${ }^{43}$.

Ahora bien, los presupuestos formales para el despliegue de la petición administrativa, en cualquiera de sus versiones - solicitudes de todo tipo, peticiones graciables, comunicaciones, algo menos en las impugnaciones-, vienen acompañados del carácter antiformalista que rige al procedimiento común peruano, pues el artículo 113 de la LPAG solo recoge ciertas obligaciones que deben ser asumidas por el contenido de estos escritos, las cuales, a su vez, se centran en la identificación y demostración de voluntad del interesado, «una exposición de los hechos y razones que fundamenten el concreto petitum $»^{44}$-incluso con clara tendencia a considerar los argumentos de derecho como residuales, pues su inclusión depende de la pertinencia y posibilidades casuísticas de los mismos-, en la indicación del órgano (autoridad) competente para conocer y resolver el expediente - aunque siempre ante error del privado cabe su tramitación de oficio merced a la aplicación de los principios de

40 GIMENO SENDRA, Vicente y otros. Los derechos fundamentales y su protección jurisdiccional. Madrid: Colex, 2007, p. 195.

41 lbíd., p. 195.

42 HURTADO YELO, Juan José. El derecho de petición en el ordenamiento jurídico español. El artículo 29 de la Constitución Española y su proyección sobre la Ley 92/60 (tesis doctoral), pro manuscrito, p. 48.

43 FERNÁNDEZ SARASOLA, Ignacio. "Comentario a la Ley 4/2001 reguladora del derecho de petición». Revista Española de Derecho Constitucional, año 22, número 65, p. 204. Resultaría interesante analizar, aunque no es la esencia de este trabajo, cuáles son los límites de este derecho constitucional. Esto a partir de situaciones cotidianas y problemáticas aparecidas en el procedimiento administrativo, tales como: ¿resultaría válida la mutación de esta figura en otro instituto como el recurso administrativo?, ¿es regular la presentación de peticiones con objetos y fines idénticos? 0 , incluso: ¿la administración queda obligada a responder todas y cada una de estas solicitudes?

44 Cierco Seira, César. Ob. cit., p. 162. 
oficialidad e indubio pro actione 45 -, en el posible señalamiento del domicilio procedimental — distinto al domicilio real, si es que así lo considera pertinente el administrado-, en la lista de anexos documentarios y en el número de expediente — si es que el procedimiento ya se inició con anterioridad-. Inclusive, como bien reconocen Abruña y Baca, aunque los escritos presentados «no reúnan todos los requisitos señalados, el interesado siempre tendrá el plazo de 2 días para subsanar cualquier omisión ${ }^{46}$, con lo cual siempre existirán, sin ninguna causal de exención para su cumplimiento, los deberes administrativos de recibir toda documentación presentada y que trate del señalamiento de defectos o descuidos formales ${ }^{47}$, y de actuaciones realizadas en ambos casos por la unidad de trámite documentario o el órgano que haga sus veces.

Puntualmente, acerca de las solicitudes de iniciación procedimental, estas aparecen configuradas mediante dos formas de legitimación activa reconocidas en los artículos 107 y 108 de la LPAG, las cuales nacen desde la extensión y la maleabilidad de la condición de interesado. En ambos casos, el Poder Legislativo ha permitido que un administrado — por sí mismo o mediante un representante— pueda señalar derechos o intereses individuales, colectivos (difusos) o de titularidad de un número indeterminado de individuales, de cara a presentar y a sostener pretensiones en un específico procedimiento. Por lo tanto, el inicio de este íter puede estar ligado a situaciones propias de la esfera jurídica de un ciudadano, o a la salvaguarda del puro y duro interés público —el bien común juridificado-. Sobre esto último, el numeral 108.2 ha puesto especial énfasis en la conexión de este tipo de solicitud con diversos supuestos problemáticos ligados a la gestión y al cumplimiento de objetivos públicos de nuestras administraciones, desde el señalamiento de deficiencias normativas de toda índole —en los que quedarían incluidos «el cumplimiento de los principios procedimentales»-, hasta de las relaciones jurídicas, de las prestaciones y de los servicios heterogéneos surgidos o entregados a los ciudadanos mediante la práctica de potestades administrativas - muchos de ellos referidos a la «calidad» e incremento de su «rendimiento»—. Todo esto a fin de llegar al cajón de sastre, el cual consiste en la presentación de sugerencias o iniciativas para obtener «un mejor nivel de satisfacción de la sociedad respecto a los servicios públicos». Aunque varias de estas opciones pudieran ser verdaderas disposiciones para incoar procedimientos nominados, formalizados y con un objeto normativamente reconocido, queda claro que varias de ellas — sobre todo las últimas referidas a las sugerencias para la mejora institucional— quedan más ligadas al régimen jurídico de las peticiones graciables.

45 En la doctrina nacional, también Morón Urbina (Comentarios a la Ley de Procedimiento Administrativo General, p. 396) ha opinado igual.

46 ABRuÑA PUYOL, Antonio y Víctor BACA ONETO. Ob. cit., p. 297.

47 Ver los numerales 125.1 y 125.2 de la LPAG. 
Por otro lado, y saliendo ya de las dos formas de inicio del procedimiento común, un tema que merece ser resaltado es que la LPAG no ha establecido ninguna actuación preliminar obligatoria antes de la emisión de cualquier acto de incoación ${ }^{48}$. De manera excepcional, y previa habilitación legal sustentada en la naturaleza de un específico procedimiento, se podrían permitir labores de fiscalización, de inspección, de aportación de datos por parte del futuro interesado o de remisiones de un informe preceptivo a un órgano administrativo distinto al encargado de la instrucción, entre otras actividades. No tenemos reconocido, como sí sucede en el ordenamiento español ${ }^{49}$, un posible «periodo de información previa o reservada para decidir al respecto con conocimiento de causa ${ }^{50}$.

Finalmente, merece un comentario aparte el efecto de interrupción de los plazos de prescripción que produce el inicio procedimental y el despliegue del término general de treinta días que tiene el o los órganos administrativos encargados de instruir, impulsar y dictar la resolución correspondiente ${ }^{51}$. Sobre lo primero, resulta claro que cualquier consolidación de la pérdida de acción procedimental en contra de un particular — si es que así estuviera establecida en una norma positiva - se vería inmediatamente suspendida apenas comience a desplegarse el procedimiento, merced a la iniciativa planteada por el posible interesado o mediante el ejercicio de las respectivas competencias administrativas de incoación. Lo segundo refiere al no perjuicio de ampliaciones en la estación probatoria solicitada por el órgano competente, o de plazos diferentes establecidos en la legislación especial, pues el término para culminar un procedimiento viene preceptuado en el artículo 35 de la LPAG, en donde se indica, de manera clara, que el tiempo «que transcurra desde el inicio de un procedimiento administrativo [...] hasta que sea dictada la resolución respectiva, no puede exceder de treinta (30) días hábiles».

\section{LOS ESTATUTOS DE LOS ADMINISTRADOS Y LA ADMINISTRACIÓN PÚBLICA ANTE EL INICIO DEL PROCEDIMIENTO ADMINISTRATIVO}

Este apartado del trabajo presenta los estatutos de los intervinientes en el procedimiento común surgidos a partir de que este se ha iniciado regularmente. Aunque aparezcan dispersas en la LPAG, debe indicarse que se tomarán en cuenta todas aquellas cuestiones que podrían resultar relevantes para comentar estas posiciones jurídicas, pero sin detenerse a revisar — para el caso de los privados- cuestiones más cercanas

\section{EL ACTO DE}

INCOACIÓNYLAS

ESFERAS JURÍDICAS

DE LOS SUJETOS

INTERVINIENTES EN

EL PROCEDIMIENTO

ADMINISTRATIVO

THE ACTION OF

INITIATING A

PROCEEDING AND

LEGAL AREAS OF

THE PARTICIPANTS

WHO ARE

INVOLVED INTHE

ADMINISTRATIVE

PROCEDURE 
a situaciones formales de habilitación, tales como la capacidad, la legitimación o la representación ${ }^{52}$.

El acercamiento al estatuto que tiene el administrado interesado pivota alrededor de un instituto poco profundizado en nuestros lares — aunque con cierto arraigo normativo y jurisprudencial por su alegación para fundamentar pronunciamientos-: el derecho al procedimiento administrativo o debido procedimiento, reconocido como principio fundamental del accionar jurídico-administrativo por el numeral 1.2 del artículo 4 del título preliminar de la LPAG. Al respecto, su intangibilidad - la cual determina el surgimiento de un auténtico derecho al trámite y a la exigencia procedimental ${ }^{53}$ - la posibilidad de permitir el complemento entre lo público y privado mediante una «equilibrada síntesis de intereses individuales e intereses institucionales $\aleph^{54}$, y la adaptación de ciertas cuestiones de los procesos judiciales han permitido crear una figura de protección y garantía de la esfera de los individuales, la que, a su vez, permite vincular a las organizaciones administrativas con ciertos preceptos legales predeterminados.

De igual manera, se ha reconocido que esta figura comporta un deber de la administración de no prescindir del cauce procedimental y de respetar sus fases para la práctica de sus potestades, así como, al mismo nivel, de respetar una serie de facultades puestas a disposición de los interesados. Estas son, por ejemplo, la transparencia administrativa, la posibilidad de exigir el impulso de la tramitación, la responsabilidad por la mala praxis del órgano competente -las responsabilidades del instructor y decisor-, la puesta en marcha de un adecuado régimen de prueba —que permita al administrado «exponer sus argumentos [...] ofrecer y producir pruebas»—, la motivación - y sus dificultades de materialización en las actuaciones diversas-, la objetividad de las personas físicas encargadas - la cual evite «funcionarios o autoridades contaminados o en situación de conflictos de intereses que puedan repercutir en la tramitación o resolución final» ${ }^{55}$-, entre otras cuestiones activas que bien pueden ser revisadas en la lista preceptuada por el artículo 55 de la LPAG.

De todo lo expuesto, existen dos derechos sobre los cuales me gustaría detenerme, ya que, aunque podrían ser objeto de un estudio individualizado, se conectan de manera más adecuada con el título del presente

\footnotetext{
52 Para una mayor profundización de estos aspectos que pertenecen al denominado «estatuto común de los interesados" pueden revisarse las relevantes aportaciones de Abruña Puyol y Baca Oneto en la obra constantemente mencionada en este estudio.

53 RIVERO YSERN, Enrique y Ricardo RIVERO ORTEGA. «El derecho al procedimiento administrativo». En Derechos fundamentales y otros estudios en homenaje al profesor doctor Lorenzo Martín-Retortillo. Volumen I. Zaragoza: Facultad de Derecho de la Universidad de Zaragoza y otros, 2008, p. 563.

54 SÁNCHEZ BLANCO, Ángel. "Sujetos, actores y factores del procedimiento administrativo". Revista de Administración Pública, número 11, 1986, p. 108.

55 Rivero Ysern, Enrique y Ricardo Rivero Ortega. Ob. cit., p. 568.
} 
trabajo. Por un lado, revisaré los llamados «administrativos» que estén vinculados — al inicio de cualquier procedimiento- a todos los titulares de derechos subjetivos o intereses legítimos. Mientras que, en segundo término, me gustaría plantear algunas líneas sobre el poco valorado derecho a la audiencia, algo retraído por el Poder Legislativo a partir de la enflaquecida regulación planteada sobre la comparecencia personal y, a reglón seguido, me gustaría otorgarle relevancia por su configuración como un medio probatorio más, capaz de ser actuado solo y a partir de la aquiescencia administrativa.

Sobre la primera de las facultades, más allá del típico análisis acerca del carácter extenso de la noción de interesado — esto según mandato del artículo 51 de la LPAG, que parte de su involucramiento con las nociones de derecho subjetivo o interés legítimo «para poder justificar la titularidad [...] la relación inmediata entre el objeto de la pretensión y quien la ejerce, perjuicio o beneficio que reporte no debe ser hipotético sino algún daño o beneficio presente o futuramente previsible» ${ }^{56}$-, resultaría interesante recalcar algunas alusiones acerca de las obligaciones que tendría la organización administrativa — con la contraparte del derecho surgido a favor de un específico administrado - de cara a la correcta conformación del inicio, del conjunto de la relación jurídico-procedimental y de las posibilidades - siempre abiertas - de nuevas intervenciones de privados en un procedimiento administrativo. Todo esto se resume en la idea de que los interesados no solo son los promotores del procedimiento - lo que viene a ser el supuesto contenido en el numeral 51.1 de la LPAG - sino, por el contrario, que en esta categoría «deberán integrarse todos aquellos [...] que a través de su solicitud den lugar a la apertura de la secuencia procedimental ${ }^{57}$ — supuesto que quedaría normativamente contenido en los interesados no iniciadores del numeral 51.2 y en el concepto genérico de tercero interesado del artículo 60-.

Ahora bien, desde el citado numeral 51.2 de la LPAG, la conformación de la condición de interesado plantea una exigencia clara puesta sobre los hombros de nuestras administraciones públicas: la práctica pertinente de los «llamados administrativos al procedimiento o a la causa» — sea al inicio o durante la tramitación del mismo— recaídos sobre aquellos administrados que pudieran resultar afectados jurídicamente por las actuaciones intermedias — por ejemplo, medidas provisionales- o definitivas - los efectos de la resolución - a adoptarse por los órganos competentes. Sobre la base de una correcta interpretación de la norma

56 ABRUÑa PuYOL, Antonio y Víctor BACA ONETO. Ob. cit., p. 245. El profesor Morón también reconoce estos postulados cuando indica que parte, interesado o administrado es «la persona física o jurídica, pública o privada, concurrentes en un procedimiento [...] en ejercicio de un interés legítimo o un derecho propio, que se relaciona con la Administración con la finalidad de ser destinarias de la declaración de voluntad final del procedimiento, y a cuyo favor o cargo, por lo general, se ejecuta el acto administrativo» (MORÓN URBINA, Juan Carlos. Ob. cit., p. 282).

57 Cierco Seira, César. Ob. cit., p. 165. 
señalada, y bajo los criterios pro homine y pro libertate, las afectaciones planteadas surgen como un nexo causal entre el sujeto involucrado y el objeto del procedimiento, y deben entenderse como posibles efectos jurídicos favorables o desfavorables surgidos desde cualquier actuación procedimental —no solamente un acto administrativo final-, y capaces de impactar directa e inmediatamente sobre la esfera jurídica de un privado - ya sea sobre sus derechos subjetivos o sus intereses legítimos-, el cual, para ser llamado, no necesariamente debe ser el propulsor del procedimiento. Esta posibilidad, que amplía el número de interesados en un procedimiento - incluso sobre administrados «no determinados»-, puede practicarse en cualquier estado de tramitación de este, bajo la condición de que debe comunicarse lo «actuado [...] mediante citación al domicilio que resulte conocido, sin interrumpir el procedimiento ${ }^{58}$. Entonces, esta obligación administrativa, en palabras de Cierco Seira, constituye el medio para dar «a conocer la tramitación de un procedimiento administrativo a aquellos sujetos, que, en principio, pueden presentar un interés en el asunto que se está ventilando, aunque no hayan participado todavía del mismo. Tomando como parangón cuando acontece en el ámbito procesal con respecto a la vocatio in ius, cabe hablar aquí de una intervención rogada o provocada por la propia Administración ${ }^{59}$ (las cursivas son nuestras).

El espíritu que está detrás de esta figura no es otro que el de evitar la indefensión de los administrados, a fin de que no se vean perjudicados por una actuación procedimental no notificada. Además, claro, de permitir identificar - no necesariamente individualizar - a todos aquellos nuevos sujetos ligados con el objeto del procedimiento, incluso $-\mathrm{y}$ de ser el caso- con la colaboración de los propios interesados que ya se encuentran participando en la tramitación del expediente ${ }^{60}$. Estas normas de la LPAG plantean un afán por parte de nuestro Poder Legislativo por mostrar una «voluntad garantista de extender la virtud del contradictorio administrativo a eventuales terceros interesados [...] Pero también confluyen razones de otra índole, vinculadas esta vez a la completud de la instrucción, esto es, a la obtención de nuevos elementos de juicio - y nuevos intereses - que permitan representar de modo objetivo la situación subyacente» ${ }^{61}$.

Un instituto del estatuto del administrado bastante amenguado en el procedimiento común preceptuado por nuestro Poder Legislativo es la audiencia —el fundamental derecho a ser escuchado por la autoridad competente- Esto, a mi modo de ver, proviene de un excesivo celo en

58 Ver el numeral 60.1 de la LPAG.

59 Cierco SeIRA, César. Ob. cit., p. 175.

60 Este deber de todo administrado, recogido en el numeral 3 del artículo 56 de la LPAG, tiene como finalidad la entrega de datos "a la autoridad [...] dirigida a identificar a otros administrados no comparecientes con interés legítimo en el procedimiento".

61 Cierco SeIra, César. Ob. cit., pp. 177-178. 
contrario, a fin de ganar una aparente fluidez en la tramitación, y por la consecuente relativización del principio audi alteram partem («escucha a la otra parte» $)^{62}$, puesto en evidencia en el articulado correspondiente de la norma legal analizada. Al menos, ambas cuestiones se desprenden de la configuración normativa bifronte de la figura, las cuales terminarían por mostrarla no como una situación activa o un derecho subjeti$\mathrm{vo}^{63}$ surgido del debido procedimiento, sino como un deber administrativo - de contenido reglado o discrecional — dependiente de la materia revisada en un concreto procedimiento para su activación.

Por una lado, este aparece conformado como una fase obligatoria para procedimientos cuyo objeto contengan intereses difusos o colectivos de diverso estilo, tales como «medio ambiental, ahorro público, valores culturales, históricos, derechos del consumidor, planeamiento urbano y zonificación; o cuando el pronunciamiento sobre autorizaciones, licencias o permisos que el acto habilite incida directamente sobre servicios públicos» ${ }^{64}$. Además, debe entenderse que la audiencia se vuelve forzosa en este tipo de actuaciones, pues es el medio necesario para lograr el correcto desenvolvimiento de la estación probatoria ${ }^{65}$ y la adopción regular de la decisión final regular ${ }^{66}$ - a partir de la aportación de datos de terceros no determinados o especificados, los cuales no son necesariamente participantes ${ }^{67}$ -

Una segunda fórmula de configuración de la audiencia sería el llamado discrecional que el órgano instructor puede hacer a los administrados -basado en diversos criterios jurídicos y extrajurídicos conectados al objeto procedimental - para que comparezcan personalmente «solo cuando así le haya sido facultado expresamente por ley» ${ }^{68}$. Este supuesto residual, necesitado de previa habilitación legal y de la expresa voluntad administrativa, y que de ninguna manera implica un derecho procedimental para el interesado, se conecta con la posibilidad de que los datos obtenidos en la audiencia previamente concedida por el órgano competente se transformen en un medio de prueba más para lograr la comprobación de hechos alegados en el curso de un procedimiento ${ }^{69}$.

Como quiera que la participación personal de los administrados es un hecho no querido —o al menos no fomentado desde la LPAG, debido a distintas razones tan valederas como discutibles-, considero que va

62 RIVERO YSERN, Enrique y Ricardo RIVERO ORTEGA. Ob. cit., p. 570.

$63 \mathrm{El}$ derecho subjetivo sería «la situación de poder concreto concedido a la persona como miembro activo de la comunidad jurídica y a cuyo arbitrio se confía su ejercicio y defensa" (BAÑo LEÓN, José María. «La igualdad como derecho público subjetivo». Revista de Administración Pública, número 114, 1987, p. 141).

64 Ver esta lista, no necesariamente cerrada, contenida en el numeral 182.1 de la LPAG.

65 Ver el numeral 182.2 de la LPAG.

66 Ver el numeral 184.4 de la LPAG.

67 Ver el numeral 184.1 de la LPAG.

68 Ver el numeral 58.1 de la LPAG.

69 Ver el numeral 3 del artículo 166 de la LPAG.

\section{EL ACTO DE \\ INCOACIÓN Y LAS \\ ESFERAS JURÍDICAS \\ DE LOS SUJETOS \\ INTERVINIENTES EN \\ EL PROCEDIMIENTO \\ ADMINISTRATIVO}

THE ACTION OF

INITIATING A

PROCEEDING AND

LEGAL AREAS OF

THE PARTICIPANTS

WHO ARE

INVOLVED INTHE

ADMINISTRATIVE

PROCEDURE 
siendo hora de una reconfiguración de esta figura, a fin de que se la acerque más al carácter contradictorio del procedimiento, a las garantías procesales mínimas - las dotaciones favorables del proceso «judicial» no deben ser abandonadas tras la búsqueda de la autonomía conceptual- y al contenido del citado principio audi alteram partem ${ }^{70}$. Creo que se ganaría muchísimo en constitucionalizar aún más nuestro procedimiento común si la audiencia se convierte en una fase procedimental más, capaz de ser exigida en cualquier caso por el participante, ya fuese cuando exista olvido, negligencia o contrariedad para su convocatoria, y sin importar cuál sea el objeto o la calidad del interés discutido. Esto, principalmente, cuando se apliquen sus reglas y principios transversales en procedimientos sancionadores, complejos -que involucran la intervención de más de una administración- o de limitación de derechos.

Por lo dicho, considero que es necesario revalorizar este viejo instituto adjetivo, no tanto para retroceder su acentuado proceso de trivialización en el ámbito del procedimiento — es decir, para detener su descomposición-, sino en pos de ganar una batalla a favor de los derechos de los privados, ya que exponer y presentar todas las formas de argumentos verbales - y confrontar así a los de la autoridad administrativa - siempre será un aliciente de eficaz consecución del propio interés público para la defensa de las posiciones jurídicas esgrimidas por los primeros - en la versión más actual presentada en el primer acápite de este trabajo-. Claro, esta «nueva» audiencia debe estar enmarcada bajo los límites correctos, que impidan la arbitrariedad de los empleados públicos con «citaciones a comparecer [...] sin mayor necesidad ni justificación, lo cual no solo es arbitrario sino agraviante del derecho fundamental a la libertad personal, sin temores injustos, desordenes de actividades personales, hostigamientos de funcionarios» ${ }^{71}$. Dichas restricciones ya tendrían algún correlato positivo en el actual artículo 58 de la LPAG, tales como la notificación previa y razonablemente antelada, la pertinencia jurídica de lo discutido en la audiencia con la materia tratada en el procedimiento, el acompañamiento del interesado por asesores - no necesariamente letrados-, la entrega de una «constancia de su comparecencia y copia del acta elaborada», la creación de auténticos métodos de realización de audiencias administrativas basados en el molde del debate oral y reglado ${ }^{72}$, entre otras cuestiones que restringirían su uso incorrecto y disfuncional.

70 Rivero Ysern, Enrique y Ricardo Rivero Ortega. Ob. cit., p. 570.

71 Morón URBINA, Juan Carlos. Ob. cit., p. 300.

72 La experiencia peruana más cercana para crear métodos de audiencia se encuentra en las reglas de juzgamiento oral preceptuadas por el nuevo Código Procesal Penal aprobado por el decreto legislativo 957. En particular, resultan rescatables y posibles de ser adaptadas al procedimiento administrativo algunas modalidades contenidas en los artículos 367 y siguientes de este dispositivo legal. 
Por lo expuesto, y como piedra de toque final, debe quedar claro que la audiencia tiene un valor muy extendido, ya que:

resulta una exigencia elemental según todos los manuales de Derecho administrativo [...] Especialmente en los procedimientos competitivos, nos parece necesario reforzar la exigencia de cumplimiento del derecho de audiencia, para aquellos interesados a los que la resolución no les vaya a favorecer. Porque una explicación previa de las razones por las que la adjudicación final de un contrato, de un empleo público, una subvención o una licencia no se va a otorgar a los aspirantes, puede favorecer la aceptabilidad de la decisión a la vez que permitir una mejor defensa de los derechos afectados antes de la consumación de los hechos ${ }^{73}$.

En último término, nos hace falta responder una pregunta: icuál sería el estatuto básico que tendría la administración pública encargada de resolver un procedimiento? Es difícil hablar de un estatuto administrativo en el mismo sentido que en el de los privados — con derechos, cargas y deberes-, pues la organización administrativa, en tanto organización del poder público sometida de suyo y por naturaleza al régimen jurídico-administrativo, no tiene más que potestades ${ }^{74}$ para manifestarse ante los sujetos destinatarios de estas. Por tanto, no tendría derechos ni libertades en titularidad. No al menos ontológicamente, cuando actúe regularmente con la «capacidad de crear, modificar o extinguir unilateralmente derechos y obligaciones y la posibilidad de imponerlos, incluso, cuando fuera necesario, coactivamente. Este poder [...] se manifiesta en una multiplicidad de aptitudes funcionales denominadas potestades, cada una de ellas conveniente a cada tipo de poder en que se diversifica el Estado» ${ }^{75}$.

Lo explicado con anterioridad nos lleva hacia una de las polémicas más extensas e interesantes aparecidas en la doctrina administrativista. Esta está referida a la posibilidad de que las personas jurídico-públicas pueden ser titulares de algunos derechos fundamentales, con lo que igualarían la condición de las personas naturales y de las personas jurídico-privadas. Esta es una discusión que, aunque pueda tener defensores en ambos lados de la orilla, lentamente se ha ido decantado por la negación de que todo poder público pueda disfrutar de derechos. Por el contrario, sobre ciertos ámbitos de ellos que pudieran ser susceptibles de protección - como las autonomías y algunas realidades procesales- deben aparecer los efectos tuitivos de la técnica de las garantías institucionales ${ }^{76}$.

73 RIVERO YSERN, Enrique y Ricardo Rivero Ortega. Ob. cit., p. 571.

74 ABRUÑa PUYOL, Antonio. Delimitación jurídica de la administración pública. Lima: Palestra, 2010, pp. 67-68.

75 lbíd., p. 74

76 ABRUÑA PUYOL, Antonio y otros autores. «Algunas ideas para el estudio de la autonomía universitaria en el ordenamiento peruano". Revista de Derecho de la Universidad de Piura, volumen 1, año 2000, p. 19.

\section{EL ACTO DE \\ INCOACIÓNYLAS \\ ESFERAS JURÍDICAS \\ DE LOS SUJETOS \\ INTERVINIENTES EN \\ EL PROCEDIMIENTO \\ ADMINISTRATIVO}

THE ACTION OF

INITIATING A

PROCEEDING AND

LEGAL AREAS OF

THE PARTICIPANTS

WHO ARE

INVOLVED INTHE

ADMINISTRATIVE

PROCEDURE 
Me inclino a pensar en dos argumentos de fondo para negar los derechos de los poderes públicos. Primero, en que estos son la proyección jurídica — en diferentes aspectos — de la dignidad humana. Es más, este valor supremo que preside, y es anterior al ordenamiento, es su presupuesto ontológico común, del que se entiende que solo las personas y sus formas creadas para colectivizar sus voluntades pueden ser partícipes ${ }^{77}$. Sin embargo, el origen posterior de los poderes públicos como organizaciones creadas por el ordenamiento para servir al ser humano —como es el caso de la administración pública mediante su objetivo no exclusivo de salvaguardar diferentes intereses ajenos- es la gran diferencia, ya que ellos tienen competencias, atribuciones y, si se quiere, el poder juridificado, puestos a su disposición como mecanismos necesarios para conseguir sus fines públicos. Por eso, bajo los lineamientos de esta división es que encajan las garantías institucionales como un medio de refuerzo para proteger las potestades que detenta un determinado poder público, puesto que impiden que otra institución le prive de estas atribuciones y, con ello, de su esencia y reconocimiento ${ }^{78}$.

Dicho esto, y asumiendo este contexto y el delicado equilibrio entre legalidad y eficacia -mencionado en el primer apartado de este trabajo- como las bases del estatuto procedimental al que quedaría sometido la administración pública, debe indicarse el conjunto de potestades administrativas involucradas en la consecución de un correcto procedimiento y de una mejor emisión de un acto definitivo o final. Al costado de ellas, o entremezcladas, se encontrarían las garantías y límites para la práctica de estas competencias - de las que ya hemos dado cuenta (en parte) en el estatuto del particular-. Pues bien, la lista de poderes incluye todas las referidas a la materia autoorganizativa, como son las estructuras de los procedimientos en cuanto a las fases, las diligencias, los trámites involucrados y los órganos competentes. En segundo término, las incluidas en el ordenamiento del personal puesto al servicio de las organizaciones administrativas, entre las cuales se encontrarían las de consecución de transparencia, el fomento de la participación ciudadana y la ética del empleado público ${ }^{79}$. Estos dos grupos van destinados a lograr el «fin primordial de una buena administración» ${ }^{80}$. Finalmente, las específicamente adjetivas referidas al inicio, a la tramitación y al término del procedimiento, se hallan muchas veces desperdigadas en varios órganos. Entre ellas se encuentran los poderes de recepción documental, el ordenación e impulso, lo referido a la actuación probatoria, a las consultivas,

77 Castillo Córdova, Luis. Comentarios al Código Procesal Constitucional. Tomo I. Lima: Palestra, 2006, pp. 32-33.

78 ABRUÑA PUYOL, Antonio y otros autores. Ob. cit., p. 24.

79 TORNOS MÁs, Joaquín. «El principio de buena administración o el intento de dotar de alma a la administración pública». En Derechos fundamentales y otros estudios en homenaje al profesor doctor Lorenzo Martín-Retortillo. Volumen I. Zaragoza: Facultad de Derecho de la Universidad de Zaragoza y otros, 2008, pp. 634-635.

80 TORNOS MÁs, Joaquín. Ob. cit., p. 633. 
a las decisorias ${ }^{81}$, a las parajudiciales, a las de imposición de medidas provisionales, a las de terminación convencional y anormal, etcétera.

Quiero terminar este trabajo - en el que el inicio del procedimiento ha sido la excusa para explayarme un poco en algunas situaciones que podrían resultar de interés - planteando una idea definitiva que ha guiado por diez años los efectos jurídicos preceptuados por la LPAG. Esta no es otra que una nueva forma de ver a la administración pública. Mi idea es verla como una organización netamente vicarial puesta al servicio efectivo del ciudadano, que actúa mediante relaciones jurídicas sometidas a cauces formales y entremezcladas con la necesidad de eficacia. Hasta ahora hemos avanzado en esa ruta —iqué duda cabe si observamos con mirada crítica los años que nos anteceden!-, sin embargo, si la juridicidad ha sido puesta en relieve con nuestro objeto de estudio, no se puede decir lo mismo del segundo elemento que compone el procedimiento. Por eso, en la actualidad, cuando la virtualidad jurídica y social de la LPAG es innegable es cuando más debemos acercarnos a un reto superior para este dispositivo y los que lo emplean, un reto centrado en que sus «reglas organizativas y procedimentales deben tener como guía la satisfacción de los ciudadanos. Su correcta aplicación debe llevarse a cabo con una sensibilidad especial que atienda este fin último» ${ }^{82}$.

\section{EL ACTO DE}

INCOACIÓNYLAS

ESFERAS JURÍDICAS

DE LOS SUJETOS

INTERVINIENTES EN

EL PROCEDIMIENTO

ADMINISTRATIVO

THE ACTION OF

INITIATING A

PROCEEDING AND

LEGAL AREAS OF

THE PARTICIPANTS

WHO ARE

INVOLVED INTHE

ADMINISTRATIVE

PROCEDURE 